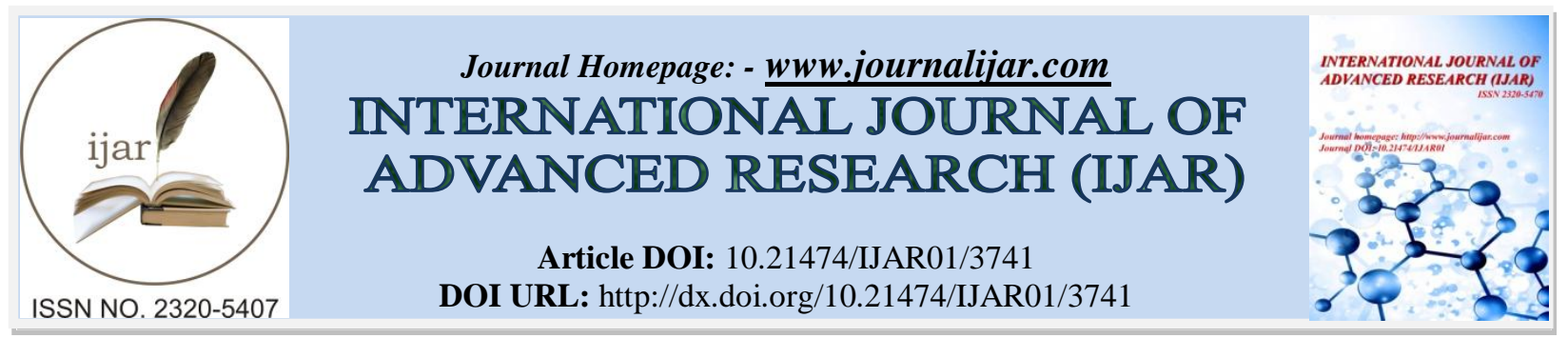

RESEARCH ARTICLE

\title{
ASSOCIATION BETWEEN GRAIN YIELD AND YIELD COMPONENTS OF MAIZE DURING INBREEDING SYSTEM.
}

Prashanth M. and Kajjidoni S. T.

Department of Genetics and Plant Breeding, University of Agricultural Sciences, Dharwad - 560 006, Karnataka, India.

\section{Manuscript Info}

Manuscript History

Received: 15 January 2017

Final Accepted: 16 February 2017

Published: March 2017

\begin{abstract}
Evaluation of cobs-to-row progenies raised from previously selected 800 progenies for their early vigour at 30 DAS and grain yield and its components at maturity indicated the presence of high degree of variation for leaf area and leaf width compared to seedling girth and seedling height. Further median and mode values of traits related to early vigour exhibited negative skewed distribution with a platykurtic pattern indicating greater scope of selection among the progenies for improving early vigour. Among the traits studied at the time of maturity cob weight, pith weight, number of kernels per cob and grain yield per plant showed high coefficient of variability. Plant height and shelling percentage exhibited very low coefficient of variation.
\end{abstract}

Copy Right, IJAR, 2017,. All rights reserved.

\section{Introduction:-}

Maize (Zea mays L.; $2 \mathrm{n}=20$ ) is an important cereal crop with high yield potential. The total production at world level has surpassed both sorghum and pearl millet gaining a third place after wheat and rice. The demand for maize grain is increasing every year due to its diversified use in poultry, piggery and industry. In India, about 50-55 per cent of maize production is consumed directly as food, 30-35 per cent for poultry, piggery and fishmeal and 10 to 12 per cent in wet milling industry viz., in starch and oil and about 3 per cent in dry milling for traditional requirement like Dalia and Sattu. A number of genotypes viz., single cross, three way cross, double top cross, double cross hybrids, composites, synthetic population are being cultivated by farmers.

The efficiency and success of hybrid maize breeding depends on the contribution of heterotic effects from the superior inbred lines. The superior cross combination may be exploited as commercial single cross. Usually, the hybrid development programme in maize involves development of inbred lines, evaluation of inbred lines, crossing of selected inbreds and production of hybrids. In this context, a programme on development of inbred lines was initiated by using inbreeding system utilizing yellow pool as the base population. Yellow pool is a blend of 50 elite lines received from Directorate of Maize Research (DMR), New Delhi and inter mated for four cycles at Agricultural Research Station, Arabhavi. The $S_{2}$ lines derived from this population were evaluated by line $\times$ tester analysis involving four diverse testers in to know their performance, combining ability and nature of inheritance of different quantitative traits. The line $\times \operatorname{tester}(\mathrm{L} \times \mathrm{T})$ design is basically an extension of top cross analysis involving more than one tester (Kempthorne, 1957). Thus, keeping these views in background, the proposed work was undertaken to develop hybrids suitable for kharif season.

Corresponding Author:- Prashanth m.

Address:- Department of Genetics and Plant Breeding, University of Agricultural Sciences, Dharwad 560 006, Karnataka, India. 


\section{*Part of the Ph.D thesis submitted to the University of Agricultural Sciences, Dharwad}

\section{Meterial and methods:-}

Fifty elite breeding lines (Table 1) were received from Directorate of Maize Research (DMR), IARI, New Delhi for development of full season heterotic yellow pool. These lines were raised and allowed to open pollinate for four generations (intermating) without exercising any selection. In each generation, the plants were raised in half-sib family method and at the end of fourth generation, the seeds were collected and grown as base population at College of Agriculture, Dharwad in isolation and allowed to open pollinate. Sufficient care was taken to maintain more than 10 thousand plant population. Out of this population, 150 plants were tagged in each grid by dividing entire population into 10 grids of $150 \mathrm{sq}$. mt. at the time of tassel emergence, based on vigour, standing ability, silk and tassel traits and free from disease incidence, 800 cobs were selected based on grain yield (per se) performance and this material formed basis for further inbreeding and isolation of inbred lines.

The experiments were laid out at Agricultural Research Station, Arabhavi and the experimental details are mentioned below under.

After thorough land preparation, hand dibbling was done with two seeds per hill and thinned out to maintain single plant per hill during second week after sowing (10-15 days after sowing). The crop was applied with recommended dose of fertilizers as per the package of practices.

\section{Observations On Quantitative Traits:-}

In these investigations, data were collected in respect of quantitative traits. Observations on quantitatively inherited traits were recorded on five competitive randomly selected plants. The average was taken as the mean of the treatment. The way in which observations were recorded is described below.

\section{Plant height at 60 days after sowing $(\mathrm{cm})$ :-}

Plant height was expressed in centimetres by measuring the plant stalk from the ground level to the base of the last leaf sheath of the plant.

\section{Ear height at 60 days after sowing $(\mathrm{cm})$ :-}

This observation was recorded at the same time as plant height (at harvest), measured as the height of the plant from the ground level to the uppermost ear bearing node and expressed in centimetre.

Leaf area at 60 days after sowing $\left(\mathrm{cm}^{2}\right)$ :-

The average of five leaves from five different plants at 60 days after sowing was calculated by using formula $\mathrm{L} \times \mathrm{B}$ $\times 0.75$ and expressed in square centimetre (Montgomery, 1911).

Ear weight (g) :-

Five ears were sun dried and weight in grams was recorded at stable moisture content.

\section{Ear length $(\mathrm{cm})$ :-}

Length of the ear was measured and recorded in centimetres at the time of harvest as its total length (from the base to the tip of the ear).

Ear circumference $(\mathbf{c m})$ :-

Ear circumference at one-third length from the base of the ear was measured and recorded in centimetre.

\section{Number of kernel rows per cob:-}

Number of kernel rows in each ear was counted for five cobs and mean was worked out.

Number of kernels per row:-

The number of kernels in any one of the row in each ear was counted and mean was worked out.

Number of kernels per ear:-

Total number of kernels in each ear of the selected plants was recorded. 


\section{Hundred grain weight $(\mathrm{g})$ :-}

One hundred randomly selected grains per cob were weighed and weight was recorded in grams.

\section{Shelling percentage:-}

The ratio of grain weight to the ear weight was expressed in percentage.

$$
\text { Shelling percentage }=
$$

\section{Grain}

\section{Cob weight}

Pith / shank / heart weight (g) :-

The total pith / shank / heart weight from each ear was recorded and the average heart weight was expressed as heart weight per plant in grams.

\section{Kernel yield per plant $(\mathrm{g})$ :-}

At the time of harvesting, fresh ear weight was recorded in grams per plant. Moisture determinations were made from shelled samples from five random ears of each plot with the help of electronic moisture meter. The fresh ear weight data was used to work out the dry weight at 15 per cent moisture grain yield in grams per plant.

\section{Kernel yield per plot (kg/plot) :-}

At the time of harvest, fresh ear weight was recorded in kilograms for each plot. This fresh ear weight was adjusted to zero per cent grain moisture and recorded as grain yield per plot. Moisture percentage was determined on universal moisture tested in a grain sample obtained from two rows of each of five ears selected at random at the time of harvest were used for genetical analysis following Combstock (1948) and Robinson (1968).

$$
\text { Yield per plot }(\mathrm{kg} / \mathrm{plot})=\quad \text { Fresh ear wejght } \times(100-\mathrm{AVM})
$$

Where,

$$
\mathrm{K}=\text { Average stand } / \text { Final } \text { stand }_{\text {trial }} \times \text { plot area } \times 0.9412
$$

$\mathrm{AVM}=$ Average moisture

Kernel / grain yield per hectare (q/ha):-

Fresh dehusked ear weight per plot was recorded at the time of harvest. Moisture content of 100 grams of fresh kernels was recorded by moisture meter of each entry and the moisture percentage was calculated by using moisture conversion charts. Kernel yield per hectare was calculated using the formula given below:-

$$
\begin{array}{ccc}
\text { Where, } \quad & \text { Yield }(\mathrm{q} / \mathrm{ha})=\frac{\text { Fresh ear weight } \times 100-\mathrm{AVM} \times \mathrm{K}}{\mathrm{K}=} \\
\mathrm{AVM}-\text { Average moisture } \quad \begin{array}{l}
\text { Final stand harvest } \\
\text { Average stand of the trial } \times \text { Area }(\text { ha }) \times 0.9412
\end{array}
\end{array}
$$

\section{Statistical Analysis:- \\ Analysis of variance:-}

$$
100 \times \text { plot area }
$$

The data were subjected to statistical analysis for randomised block design (RBD) as described by Panse and Sukhatme (1962). The mean values of the entries in each replication were used for analysis of variance (ANOVA). The significant difference among genotypes was tested by ' $F$ ' test at one per cent and five per cent levels of probability.

\section{Genotypic and phenotypic correlation coefficients:-}

Genotypic and phenotypic correlation coefficients were worked out as per the methods suggested by Johnson $e t$ al. (1955) to find out the relationship between yield and its contributing characters. Analysis of covariance was done similar to that of analysis of variance taking two characters at a time. The genotypic and phenotypic co-variances were derived as detailed for genotypic variance. The genotypic and phenotypic variance and co-variance components were utilized to calculate genotypic and phenotypic correlation coefficients (r) by applying the formula.

Where,
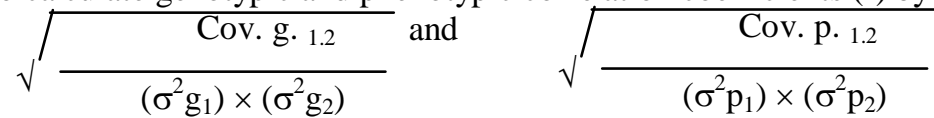


$\begin{array}{ll}\text { Cov.g. } 1 \cdot 2 & \text { : Genotypic covariance between two traits (1 and 2) } \\ \text { Cov.p. } 1 \cdot 2 & \text { : Phenotypic covariance between two traits (1 and 2) } \\ \sigma^{2} g_{1} & : \text { Genotypic covariance for first trait } \\ \sigma^{2} p_{1} & : \text { Phenotypic covariance for first trait } \\ \sigma^{2} g_{2} & : \text { Genotypic covariance for second trait } \\ \sigma^{2} p_{2} & : \text { Phenotypic covariance for second trait }\end{array}$

Referring to correlation table of Snedecor and Cochran (1967), the significance of penotypic correlation coefficient was tested.

\section{Results:-}

Association studies in $S_{1}$ progenies:-

Among all traits, selection for seed yield is a complex phenomenon that involved interaction among different growth and yield contributing character of a genotype. In the present investigation an attempt was made to understand association of different traits at population level contributing towards yield improvement.

The phenotypic and genotypic correlation of grain yield with 16 other yield components among $\mathrm{S}_{1}$ progenies were worked out and the same is presented in Table 2 and 3.

A general observation of the data across different characters under study revealed that seed yield exhibited significant positive correlation with few yield traits, but also exhibited significant negative association with few other traits. The results obtained on the basis of association of individual trait with grain yield are presented below.

\section{Plant height at 60 days after sowing $(\mathrm{cm})$ :-}

Plant height at 60 DAS showed highly significant association in positive direction with other traits under study except for shelling percentage which had non-significant association with this trait (0.086) only at genotypic level (Table 2). Whereas highly significant phenotypic association was recorded in desirable direction, except for number of kernels per rows (0.112) which expressed only significant association in positive direction (Table 3 ).

\section{Ear height (cm):-}

All the traits exhibited highly significant positive association with the ear height, except shelling percentage (0.072) which was non-significant at genotypic level (Table 2). A highly significant positive phenotypic association was recorded for all the traits studied, except for plant girth at 30 DAS (0.108), leaf area at 30 DAS (0.121), number of kernel rows per cob (0.110) and number of kernels per row (0.123), at five per cent level of probability (Table 3 ).

\section{Leaf area at 60 days after sowing $\left(\mathrm{cm}^{2}\right)$ :-}

The data revealed significant positive genotypic association with all traits except for number of kernel rows per cob (0.028), shelling percentage (0.082) and number of grains per cob (0.184) which recorded non-significant association (Table 2).

A highly significant positive phenotypic association was recorded for all the traits studied, except for number of kernel rows per cob (0.036) and shelling percentage (0.070) (Table 3).

\section{Cob weight $(\mathbf{c m})$ :-}

All the traits exhibited highly significant association with cob weight at both genotypic and as well as phenotypic level in the desirable direction (Table 2 and 3 ).

\section{Cob length $(\mathrm{cm})$ :-}

The trait cob length exhibited highly significant positive genotypic association with all the characters, except for number of kernel rows per cob (0.062) and shelling percentage (0.061) (Table 2). A similar association of cob length with all the characters at phenotypic level was exhibited except for plant height at 30 DAS (0.122), number of kernel rows per cob (0.068) and shelling percentage (0.053) (Table 3).

\section{Cob girth $(\mathbf{c m})$ :-}

It is interesting to note that all the traits under study exhibited highly significant association in the desirable direction in both genotypic as well as phenotypic level with cob weight (Table 2 and 3 ). 


\section{Number of kernel rows per cob:-}

Majority of the characters exhibited highly significant positive genotypic association with number of kernel rows per cob, except for the traits like, number of kernels per row (0.101), leaf area at 60 DAS $(0.028)$ and cob length $(0.062)$ (Table 2). Similarly, a highly significant positive phenotypic association was recorded for all the traits studied, except the characters like plant girth at 30 DAS (0.117), leaf area at 30 DAS (0.127), ear height (0.110), number of kernels per row (0.103) and shelling percentage $(0.125)$, which recorded significance only at five per cent level of probability (Table 3). But, the traits such as leaf area at 60 DAS (0.036) and cob length (0.068) exhibited nonsignificant association.

\section{Number of kernels per row:-}

A highly significant positive genotypic association with number of kernels per row was observed for all the characters under study, except for number of kernel rows per cob which exhibited significance at five per cent level of probability in positive direction (0.101) (Table 2). Similarly, with phenotypic correlation, trait under study had highly significant positive association with all the characters except for plant girth at 30 DAS (0.102), plant height at 60 DAS (0.112), ear height (0.123) and number of kernel rows per cob $(0.103)$ which exhibited only a positive significant association at five per cent level of probability (Table 3 ).

\section{Pith weight (cm):-}

The study revealed that the trait pith weight exhibited highly significant association at one per cent and five per cent level of probability with all the traits under study at genotypic and phenotypic levels, except with shelling percentage which had significance in negative direction (Table 2 and 3).

\section{Hundred seed weight (g):-}

From the results of present study, it is clear that all the characters exhibited highly significant association with 100seed weight at both genotypic and phenotypic levels, except for number of kernel rows per cob (0.121) which recorded positive association with phenotypic level at five per cent level of probability (Table 2 and 3 ).

\section{Shelling percentage $(\%)$ :-}

The character shelling percentage exhibited highly significant positive genotypic association with all the traits under study, except for plant height at 30 DAS (0.115) which recorded only significant positive association (Table 2$)$. The characters plant girth at 30 DAS $(0.039,0.009)$, plant height at 60 DAS $(0.086,0.075)$, ear height $(0.072,0.056)$, leaf area at 60 DAS $(0.082,0.070)$ and cob length $(0.061,0.053)$ exhibited non-significant association, whereas pith weight $(-0.450,-0.450)$ recorded highly significant negative association at both genotypic and phenotypic levels (Table 2 and 3). Similarly at phenotypic level, a highly significant positive association was recorded for all the traits, except for plant height at 30 DAS (0.103), leaf area at 30 DAS (0.102) and number of kernel rows per cob (0.125) at five per cent level of probability (Table 2 and 3 ).

\section{Number of kernels per cob:-}

Number of kernels per cob recorded highly significant positive association at both genotypic and phenotypic levels, except for leaf area at 60 DAS (0.184) which showed non-significant association at genotypic level (Table 2 and 3 ).

\section{Grain yield per plant $(\mathrm{g})$ :-}

In maize, increase in grain yield is mainly achieved by manifestation of many characters like number of kernel rows per cob, number of kernels per row, cob length, cob girth, 100-seed weight, etc. Therefore it is necessary to understand the nature of association existing between all characters and grain yield, particularly in early generation $\left(\mathrm{S}_{1}\right)$.

Grain yield per plant had highly significant positive association with all the characters at both genotypic and phenotypic levels, except for plant girth at 30 DAS (0.393) which showed significance only at five per cent level of probability at genotypic level (Table 2 and 3).

\section{Discussion:-}

In general genotypic correlation was higher in magnitude than that of phenotypic correlation. Similar trend of higher values of genotypic correlation coefficients than phenotypic coefficient correlation was also reported in earlier studies. Muhammad Rafique et al. (2004) reported higher GCV in case of grain yield per plant followed by plant height, ear height, kernels per row, 1000-kernel weight and ear length. Number of kernels per row had significant 
correlation with seed yield followed by plant height, ear height, cob diameter and length of cob. Similar results were also reported by earlier worker, Khatum et al. (1999) and Devi et al. (2001).

Grain yield per plant exhibited positive association with all growth and yield parameters in the present investigation. Most of the growth and yield parameters are inter dependent as evidenced by significant and positive correlation among themselves. However, number of kernel rows per cob was not associated significantly with leaf area and cob length indicating these as independent traits. Likewise shelling percentage was also found to be independent of plant girth at 30 DAS, plant height at 30 DAS, ear height at 30 DAS, leaf area at 60 DAS and cob length as it has recorded non-significant correlation with these traits. As expected pith weight exhibited significant and negative association with shelling percentage, which are interdependent among the productivity traits. Cob weight, cob length, cob girth, grain number per cob, number of kernels per cob, 100-seed weight and shelling percentage recorded high correlation coefficient more than 0.50 indicating these are important yield contributing traits. Similar reports were also made by Kumar (1974), Bhalla and Khehra (1977) and Ramamurthy (1980).

\section{References:-}

1. Bhalla, S. K. and Khehra, A. S., 1977, Analysis of combining ability in maize at varying plant densities. Maydica, 22 : 19-26.

2. Comstock, R. E. AND ROBINSON, H. F., 1948, The components of genetic variance in populations of biparental progenies and their use in estimating average degree of dominance. Biometrics, $4: 254-266$.

3. Devi, I. S., Muhammad, S. and Muhamad, S., 2001, Character association and path coefficient analysis of grain yield and yield components in double crosses of maize. Crop Research, Hisar, 21 : 355-359.

4. Johnson, H. W., Robinson, H. F. and Comstock, R. F., 1955a, Estimation of genetic and environmental variability of soybean. Agronomy Journal, 47 : 314-318.

5. Kempthorne, O., 1957, An Introduction to Genetic Statistics.John Willey and Sons, New York.

6. Khatum, F. S., Begum, A., Motin, S. Y. and Islam, M. R., 1999, Correlation coefficient and path coefficient analysis of some maize hybrids. Bangladesh Journal of Botany, 28 : 9-15.

7. Kumar, S., 1974, Correlation between yield and yield components and their combining ability in maize. Madras Agricultural Journal, 61 : 111-117.

8. Muhammad Rafique, Amer Hussain, Tariq Mahmood, Abdul Wadood ALVI and Bashir Alvi Ayub, M., 2004, Heritability and interrelationship among grain yield and yield components in maize (Zea mays L.), Alvi Ayub Agricultural Institute, Faisalabad, Pakistan. International Journal of Agricultural Biology, 6 : 1113-1114.

9. Panse, V. G. and Sukhatme, P. V., 1962, Statistical Methods for Agricultural Workers, ICAR Publication, New Delhi, p. 145.

10. Robinson, N. G., 1968, Genetic variance estimates from different mating systems in a variety of corn (Zea mays L) Diss. Abstr., 28 : 2214B-2215B.

11. Ramamurthy, A., 1980, Genetic analysis of some quantitative characters in maize (Zea mays L.). Mysore Journal of Agricultural Sciences, 14 : 126.

12. Snedecor, G. W. and Cochran, W. G., 1967, Statistical Methods, Oxford and IBH, New Delhi, p. 338. 